\title{
First Example of Intermolecular Palladium-Catalyzed Asymmetric Allylic Alkylation of Hydroxyacrylates: Synthesis of All-Carbon $\alpha$-Aryl Quaternary Carbonyl Compounds
}

\author{
Sharif A. Asad \\ M. Mahmun Hossain* \\ Synthesis 2016, 48, 200.
}

The authors withdraw the invited article Synthesis 2016, 48, 200 upon request of the Editor in Chief for reasons of significant content overlap with a previously published short communication. ${ }^{1}$ The authors realize that the Eur. J. Org. Chem. publication has not been referenced. The Editor in Chief recognizes that, had the submission to Eur.J. Org. Chem. been referenced and its contents disclosed, the striking similarities would have been noted and the manuscript would not have been accepted for publication.

(1) First Example of the Intermolecular Palladium-Catalyzed Asymmetric Allylic Alkylation of Hydroxyacrylates: Synthesis of All-Carbon $\alpha$-Aryl Quaternary Aldehydes, S. A. Asad, J. Ulicki, M. Shevyrev, N. Uddin, E. Alberch, M. M. Hossain Eur. J. Org. Chem. 2014, 5695-5699. 